\title{
Development and Validation of a Nutritional Health Education Program for Health Care Providers in Geriatric Homes
}

\author{
Dina. A. Abdel Raouf,MSc', Tomader T. Abdel Rahman,MD², Ghada E. Amin, MD, Maha \\ M. El Gaafary,MD, Diaa M. Abdel Hamid,MD, Mohamed Y. El Awady,MD. \\ (1)Community, Environmental and Occupational Medicine department, (2Geriatrics and \\ Gerontolongy department, Faculty of medicine, Ain-Shams University, Egypt.
}

Objectives: To develop and implement a health education program for health care providers (HCPs) in geriatric homes about nutrition in Elderly and to evaluate the program in terms of: HCP's knowledge before and after the program, and to assess nutritional status of elderly served by HCP before and after the program and also to measure the frequency of different malnutrition risk factors in elderly at geriatric homes.

Subjects and methods: Randomized Clustered Controlled Clinical Trial was conducted on 240 elderly residing in 6 geriatric homes randomly selected. Three homes were assigned randomly to study group and three for control group. Elderly residing in the assessd geriatric homes aged between 60-75 years were included in the study. Health care providers (HCP) recruited was subdivided into 2 groups; study group and control group. HCP in the study group were subjected to a nutrition education program that was not administered to the control group.

Results: There was improvement in knowledge of HCPs after the intervention health education program regarding elderly nutrition compared to the baseline knowledge and also to control group $(\mathrm{p}<0.005)$. There was a statistical significant difference in the rate of weight loss which was declined over a period of 4 months from the beginning of the study on June 2012 till October 2012 in both groups ( $p<0.001$ ), but the rate of weight loss had declined after the intervention at the end of the study in the study group compared to the control group. Most of the elderly were overweight BMI >30 (67.1\%). Nearly half of the elderly $(52.9 \%)$ were at risk of malnutrition with the MNA (Mini Nutritional Assessment) score (17.1-23.5). The majority of the elderly $98.8 \%$ were at risk of significant weight loss of at least $5 \%$ within 6 months by using the Appetite Assessment tool score with sum of score $<=14$. The majority of the elderly $(98.3 \%)$ had a dental problem as(loss of teeth, eating difficulty, dry mouth or lesions) that may affect health and nutritional well-being with a score of $>=2$ by using Dental screening tool. There was improvement in physical aspect of quality of life in terms of activities and instrumental activities of daily living after implementation of the nutrition health education program in the study group compared to control group $(\mathrm{p}<0.001)$

Conclusion: Geriatric homes need continuous monitoring and reinforcement of health education of the health care providers and this will be reflected on the nutritional status and well being of the elderly residing in these Geriatric homes. Raising the awareness of the elderly is needed to improve not only the nutritional state but also the physical and psychological aspects of quality of life to have better health outcomes and good healthy elders.

Keywords: Health Care Providers, Geriatric Homes, Nutritional Health education program. 


\section{Introduction}

Nutrition is an important determinant of health in elderly patients. Over the past decade, the importance of nutritional status has been increasingly recognized in a variety of morbid conditions including cancer, heart disease, and dementia in persons over the age of $65^{(1)}$. Routine screening of Patients to identify risk of malnutrition has been recommended by many national, international and specialist organizations ${ }^{(2)}$.

Although there is no uniformly accepted definition of malnutrition in the elderly, some common indicators include involuntary weight loss, abnormal body mass index (BMI), specific vitamin deficiencies, and decreased dietary intake are used to detect malnutrition (3). Malnutrition in older patients is regularly under-diagnosed ${ }^{(4)}$ and many physicians have expressed their need for more education regarding nutritional status in older patients ${ }^{(5)}$. Health practitioners may not readily recognize weight loss in the elderly as a morbid symptom of malnutrition because some weight loss may be associated with age-related reductions in muscle mass (6).

Many elderly patients have an increased risk for malnutrition compared with other adult populations. It is estimated that between $2 \%-16 \%$ of community-dwelling elderly are nutritionally deficient in protein and calories (7).

If mineral and vitamin deficiencies are included in this estimate, malnutrition in persons over the age of 65 may be as high as $35 \%$ ( 82 .The situation for hospitalized seniors is also disturbing. Studies of hospitalized older patients suggest that between $20 \%-65 \%$ of these patients suffer from nutritional deficiencies ${ }^{(9)}$.
The prevalence of malnutrition in long-term care facilities is estimated to be between $30 \%-60 \%^{(10)}$.

The purpose of nutrition screening is to identify malnourished individuals or those at risk of becoming malnourished, so that more extensive and comprehensive nutritional assessment can be performed and intervention and plan of care is implemented (11). The Mini Nutritional assessment (MNA) was one of the tools that was developed to evaluate the risk of malnutrition in the elderly in general practice and upon admission to a nursing home or hospital ${ }^{(12)}$.

The sequale of malnutrition include physical, mental and social disability. If inadequate dietary intake continues for a long time (weeks or months) under nutrition results. If under nutrition is extreme, it results in diminished muscle mass, functional impairment and decreased Health related Quality Of life ${ }^{(13)}$.Therefore diet and exercise modulate the rate of functional decline with age and can be used to delay or postpone the onset of disability or dysfunction $^{(14)}$.

Quality of life is a concept that includes physical and mental well being. In its broadest and most inclusive sense it is sometimes referred to as "life satisfaction". The relationships between nutrition, aging and quality of life are recursive. Agingassociated factors alter certain aspects of nutrition, such as the sense of smell and taste, ability to chew and swallow, and gastrointestinal and bowel function, and these in turn may influence quality of life. At the same time, poor nutrition and lack of physical activity can lead to lack of appetite, inability to perform activities of daily living, changes in quality of life, morbidity and mortality ${ }^{(15)}$. 


\section{Methods:}

A Randomized clustered Controlled Clinical Trial was conducted in a sample of geriatric nursing homes in Cairo governorate. The study was targeting geriatric homes of low to moderate social class that was identified by the fees administered by elders. All elder between the ages of 60 to 75 years old age were given the chance to be enrolled in the study including bed-ridden. Elder with difficulty for applying the assessment tools on them were excluded from the study. Three homes were randomly assigned to the study and 3 for the control group. Health care providers (HCPs) recruited from these homes were subdivided into 2 groups; study group and control group. HCPs in the study group were subjected to a nutrition education program that was not administered to the control group.

Study Setting and Period of the Study: Six Geriatric Homes of low to moderate social class. The Study Was conducted on June 2012, the intervention started at the end of October 2012 and the study ended on August 2013

\section{Sampling:}

HCP Sampling: A change in nutrition knowledge was expected to range from $10 \%$ before the program to $50 \%$ after the program , this would yield a sample size of 30 HCPs in each of study and control groups at 0.05 alpha error and 0.80 power of the test.

Elderly Sampling: Assuming a change in UWL (Unintended Weight Loss) to range between $30 \%$ (before the program) to $10 \%$ (after the program) a sample size of 120 elder in each group is enough to detect such difference at 0.05 alpha error and 0.80 power of the test.
Nursing Home Sampling: Six (6) Nursing Homes were enough to fulfill the calculated sample size from HCP and elderly. They were randomly selected from a list of available geriatric homes in Cairo governorate. Permission for study conduction from nursing homes managers had limited the selection chance as some managers did not accept participation in the study. From the 6 nursing homes that agreed to participate in the study 3 were assigned randomly to study group and 3 for control group.

The Intervention "The Health Education Program":

A bundle of interactive lectures and focus group discussion was provided along a period of 3 days to be repeated for 3 times during a total period of 1 year. Those sessions were reinforced by provision of brochures containing illustrated information about nutrition in elder and examples of diet for elder with different morbid conditions. The intervention started on October 2012, and the series of lectures were repeated on March 2013, and then repeated again and finally in August 2013.

Evaluation of the Health Education Program:

The Nutritional Knowledge of HCP was evaluated by administering the translated and revised form of Nutritional Awareness

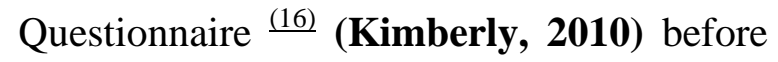
and after the program in the 2 groups. UWL (Unintended Weight Loss) was monitored every 2 months. A weight loss of more than $5 \%$ in 3 months or more than $10 \%$ in 6 months was considered as UWL. Quality of life (QoL Physical and Psychological aspects) were assessed before and after the program. 
Data collection Tools:

Nutritional screening: Mininutritional assessment (MNA) checklist was used to identify different nutritional risk factors among elder. This tool classifies elder as "at risk" of malnutrition (score of 8-11 points), "malnourished" (score of 0-7 points) and "Normal nutritional status" (score of 12-14 points). An Appetite assessment tool was used to predict weight loss if the total score is less than 14. Dental screening tool with a score $\geq 2$ indicates a dental problem that may affect eating function and consequently nutritional status.

\section{Anthropometric}

measurement

assessment: Weight of the served elderly was recorded at the beginning and the end of the study and at regular intervals (every 2 months) and unintended weight loss was reported. Other measurements include: weight, height, knee to ankle length, body mass index (BMI), mid arm circumference (MAC) and calf circumference.

Nutritional Knowledge Questionnaire: The knowledge of Health care providers regarding different aspects of elderly nutrition was assessed before and after the program by using the translated and revised form of Nutritional Awareness Questionnaire ${ }^{(16)}$.

Instrumental activities of daily living:_The total score may range from 0-8. A lower score indicates a higher level of dependence.

Activities Of Daily Living: The total score range from 0-6. The index of independence in ADL is based on the evaluation of the functional independence or dependence of patients

Geriatric Depression Scale: A score 5 or more indicates positive screening for depression.
Ethical consideration: Research conduction approval was obtained from Ain -Shams University Ethical Committee and geriatric homes

Statistical Analysis: The data was entered and analyzed using a statistical package for Social Sciences Program SPSS package version 20. Data were presented by descriptive statistics in form of frequencies $\&$ percentages for qualitative variables. Paired $\mathrm{T}$ test was used for analysis of Quantitative data \& level of significance considered statistically significant (p- value $<0.005)$.

Results:

Table (1): shows that there was a high statistical significant difference between both study \& control groups regarding knowledge concerning Elderly nutrition after the nutritional health education program ( $\mathrm{p}<0.001)$, however the base line knowledge was nearly the same in both groups $(\mathrm{p}>0.005)$

Table (1) Scores of Both Study and Control Groups before and after intervention at the end of the Study

\begin{tabular}{llll}
\hline & $\begin{array}{l}\text { Before } \\
\text { Mean (SD) }\end{array}$ & $\begin{array}{l}\text { After } \\
\text { Mean (SD) }\end{array}$ & $\begin{array}{l}\text { P } \\
\text { value }\end{array}$ \\
\hline Study & $11.37(2.25)$ & $18.53(2.62)$ & $\begin{array}{l}\mathbf{0 . 0 0 0} \\
*\end{array}$ \\
Control & & $11.53(1.59)$ & 0.119 \\
& $12.17(1.95)$ & & \\
\hline $\begin{array}{l}\text { P } \\
\text { value }\end{array}$ & 0.147 & $0.000 *$ & - \\
\hline
\end{tabular}

* Statistical Significant difference 
Table(2.1) shows Age and Gender Distribution of Elder in both Study and Control Group, the majority of elderly aged $75 y e a r s$ or more with Mean value was 75.86(5.54). As regard the Gender, females represented more than half of the elderly (52.9).

Table (2.1): Age and Gender Distribution of Elder in the Study and Control Group

\begin{tabular}{|c|c|}
\hline Variable & Statistic \\
\hline \multicolumn{2}{|l|}{ Age } \\
\hline$\circ \mathbf{6 0}-$ & 1 \\
\hline ○ $65-$ & 7 \\
\hline ○ $70-$ & 107 \\
\hline ○ $\mathbf{7 5}+$ & 125 \\
\hline Mean (SD) & $75.86(5.54)$ \\
\hline \multicolumn{2}{|l|}{ Gender: N (\%) } \\
\hline ○ Male & $113(47.1)$ \\
\hline$\circ$ Female & $127(52.9)$ \\
\hline
\end{tabular}

Tables(2.2): shows that there was a no significant decline in weight among the study group by the end of the study compared with control group which had statistically significant decline in mean weight which means improvement in nutritional status and effective educational program in comparison to the control group which had a higher rate $(\mathrm{p}<0.005)$

Table (2.2): Mean weight in Elder in the Study and Control Groups Before and after intervention at the End of the Study

\begin{tabular}{llll}
\hline & $\begin{array}{l}\text { Before } \\
\text { Mean(SD) }\end{array}$ & $\begin{array}{l}\text { After } \\
\text { Mean (SD) }\end{array}$ & $\begin{array}{l}\text { P } \\
\text { value }\end{array}$ \\
\hline $\begin{array}{l}\text { Weight } \\
\text { Study }\end{array}$ & & & \\
Control & $74.65(4.99)$ & $74.46(4.88)$ & $\mathbf{0 . 1 9 8}$ \\
& $78.14(4.61)$ & $77.62(4.65)$ & $\mathbf{0 . 0 0 2 *}$ \\
\hline P value & $\mathbf{0 . 0 0 0 *}$ & $\mathbf{0 . 0 0 0 *}$ & - \\
\hline
\end{tabular}

* Statistical Significant difference

Table(3):shows that there was improvement in the physical aspect of quality of life of elderly in the study group presented in the scores of activities and instrumental activities of daily life by the end of the study in comparison to the control group and the difference was statistically significant (p $<0.001$ )

Table (3): ADL and IADL Score among Elder in the Study and Control Group Before and After Intervention

\begin{tabular}{llll}
\hline & $\begin{array}{l}\text { Before } \\
\text { Mean } \\
(\mathbf{S D})\end{array}$ & $\begin{array}{l}\text { After } \\
\text { Mean } \\
\text { (SD) }\end{array}$ & $\begin{array}{l}\mathbf{P} \\
\text { value }\end{array}$ \\
\hline ADL & & & \\
Study & $3.22(2.77)$ & $4.47(1.14)$ & $\mathbf{0 . 0 0 0 *}$ \\
\hline Control & $2.71(2.51)$ & $2.60(1.74)$ & $\mathbf{0 . 6 8}$ \\
\hline P value & 0.139 & $0.000^{*}$ & - \\
\hline IADL & & & \\
Study & $3.22(2.06)$ & $4.62(1.31)$ & $\mathbf{0 . 0 0 0 *}$ \\
\hline Control & $2.40(1.98)$ & $1.99(1.30)$ & $\mathbf{0 . 0 6}$ \\
\hline P value & & \multicolumn{2}{|l}{} \\
\hline
\end{tabular}

* Statistical Significant difference

Discussion:

The present study showed that there was deficiency in the knowledge of health care providers regarding elderly nutrition as the mean of the base line knowledge in the study group was 11.37 (40.6\%) $\mathrm{SD}=2.25$, while it was about $12.7(43.45 \%) \mathrm{SD}=1.94$ in the control group, but after intervention the mean knowledge of health care providers in study group had improved to reach $18.53(66.19 \%) \mathrm{SD}=2.62$, while it nearly remained the same $11.53(41.19 \%) \mathrm{SD}=1.59$ in control group who did not receive the nutritional educational problem. 
In a study of Canadian community health nurses, a 50 item multiple choice questionnaire developed by the authors to assess the nutrition knowledge of community health nurses, the mean was 69\% (SD = 8), Lindseth (1994) modified the 50 item - Nutrition for Nurses questionnaire used in the Canadian study to test nutrition knowledge of 176 Nurses working in 39 nursing homes, hospitals, and community/public health agencies. Mean score was 32.5\% (SD $=6$

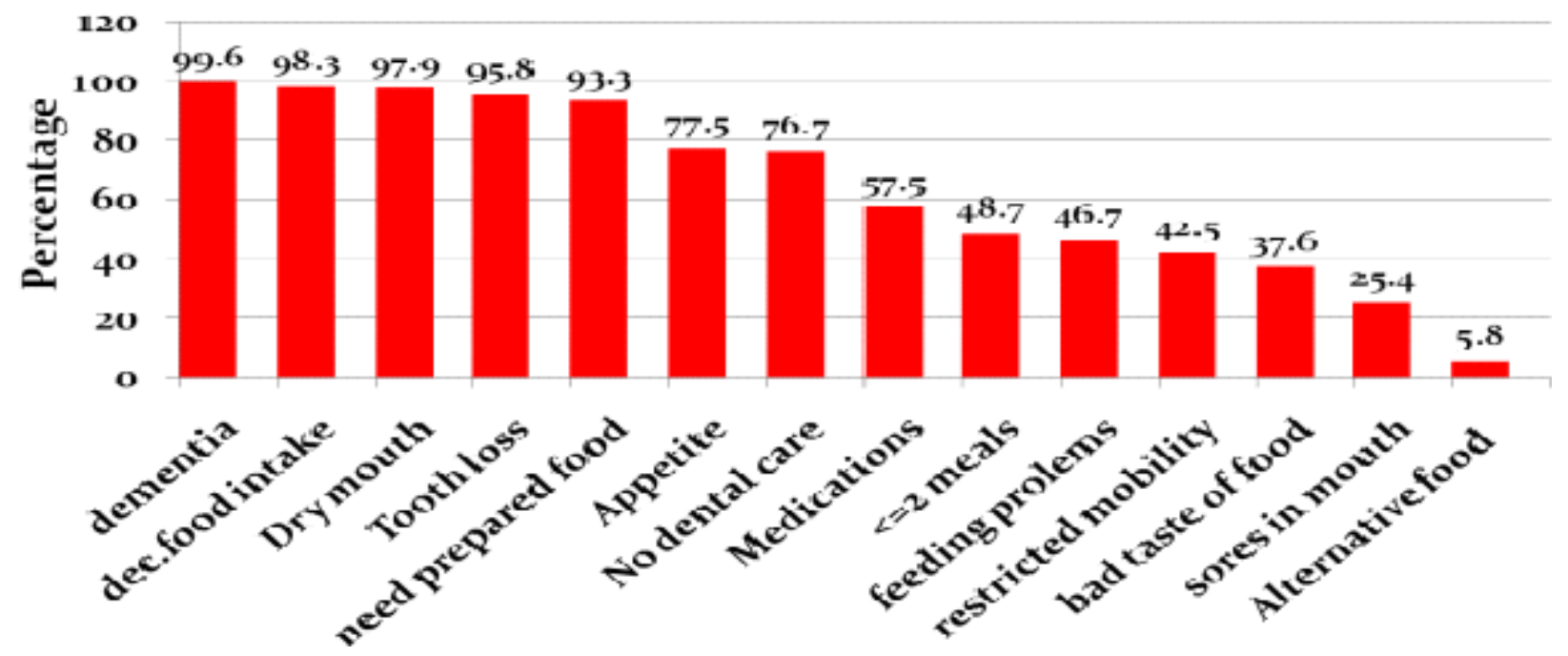

Figure (1) shows frequency distribution of different malnutrition risk factors in elderly

In the current study nearly half of the elderly residents suffered from weight loss which was $50.9 \%$ in the study group and $49.1 \%$ in the control group before the intervention Nutritional Health education program. These findings also correlate with ${ }^{172}$ who estimated that $60 \%$ of nursing home residents lose weight while other studies found between $33 \%$ and $85 \%$ were malnourished ${ }^{(18)}$.There was a no significant decline in mean weight among the study group by the end of the study compared with control group which had statistically significant decline in mean weight which means improvement in nutritional status and effective educational program in comparison to the control group which had a higher rate $(\mathrm{p}<0.005)$

The functional ability of elderly residents in the form of activities of daily life and instrumental activities of daily living have been improved by the end of the study, this can be explained by improvement in nutritional status of the elderly in the study group.

Studies showed that increasing physical activity is a viable strategy for improving both health and quality of life of older adults ${ }^{(19)}$. Stewart and King proposed two outcome categories (Functioning and well being) to measure the effect of physical activity on the overall quality of life. Functioning included physical activity, cognition and activities of daily living ${ }^{(19)}$ 


\section{Conclusion:}

Health care providers in both study and control groups nearly had the same level of baseline knowledge regarding elderly nutrition. There was a significant statistical difference between scores of baseline knowledge and scores after intervention among health care providers in the study group, compared to the control group.

There was a no significant decline in mean weight among the study group by the end of the study compared with control group which had statistically significant decline in mean weight which means improvement in nutritional status and effective Health education nutritional.

There was also improvement in physical aspect of quality of life in terms of activities and instrumental activities of daily living after implementation of the nutrition health education program in the study group compared to control group 


\section{References:}

1. Basran JF, Hogan DB. Vitamin E and Alzheimer disease. Geriatr Aging.2002;5:8-12.

2. British Dietetic Association . Nutrition Screening Tools. Professional Development Committee Briefing Paper no. 9. Birmingham: British Dietetic Association.1999

3. Reuben DB, Herr KA, Pacala JT. Geriatrics at your fingertips. 6th ed. Malden, MA: Blackwell Publishing,2004.

4. Gariballa SE. Nutritional support in elderly patients. $J$ Nutr Health Aging. 2000;4:25-7.

9. age. Eur $J$ Clin Nutr. 2002;56(Suppl 3):S73-6.

10. -Elmstahl S, Persson M, Blabolil V. Malnutrition in geriatric patients: a neglected problem? $J$ Adv Nurs. 1997;26:851-5.

11. Rudman D, Feller AG. Proteincaloric malnutrition in the nursing home. $J \mathrm{Am}$ Geriatr Soc. 1989;37:173-83.

12. Green S.M , Watson R. Nutritional screening and assessment tools for older adults. Journal of advanced nursing,2006 ;54(4):477-90.

13. Yitshal N Berner . Assessment tools for nutritional status in the elderly. IMAJ . 2003;5:365-67.

14. Muhlethaler R, Stuck A, Minder C, Frey B. The prognostic significance of protein-energy malnutrition in geriatric patients . Age Ageing. 1995;24:193-197.

15. Blumberg J. Nutrition needs of seniors. J Am Coll Nutr. 1997;16:517-23.

16. Amarantos E, Martinez A and Dwyer J. Nutrition and quality of life in older adults. Journal of Gerotology Biol Sci Med Sci . 2001; 56A (Special issue 2):54-64.

17. Kimberlypenland"The relationship between nurse nutrition knowledge and unintentional
5. Mihalynuk TV, Knopp RH, Scott CS. Physician informational needs in providing nutritional guidance to patients. Fam Med. 2004;36:722-6.

6. Kane RL, Ouslander JG, Abrass IB. Essentials of clinical geriatrics. 3rd ed. New York: McGraw-Hill; 1994.

7. Whitehead C, Finucane P. Malnutrition in elderly people. Aust N Z J Med. 1997;27:68-74.

8. Chandra RK. Nutrition and the immune system from birth to old

weight lossin Nursing Home Resident", 2010.

18. Curfman, C. Managing dysphagia in residents with dementia. Nursing Homes: Long-Term Care Management. e-Newsletter (2007)

19. Burger, S., Kayser-Jones, J., \& Bell, J. Food for thought: Preventing/treating malnutrition and dehydration. Contemporary Long-term Care, (2001);24 (4), 24-28.

20. Rejeski WJ, Mihalko SL. Physical activity and quality of life in older adults. J Gerontol Biol Sci Med Sci, 2001; 56A (2):23-35. 
Dina. A. Abdel Raouf et al.EJGG.2014; 1(1):60-67. 